\title{
ERRATUM
}

Bao-Ming Ge $\cdot$ Tian-Pei Guan · David Powell

William J. McShea • Yan-Ling Song

\section{Erratum to: Effects of an earthquake on wildlife behavior: a case study of takin (Budorcas taxicolor) in Tangiahe National Nature Reserve, China}

\section{Erratum to: Ecol Res}

DOI 10.1007/s11284-010-0759-2

Unfortunately, Fig. 4a, b appears incorrectly in the article cited above. The corrected figures are shown here.
The online version of the original article can be found under doi:10.1007/s11284-010-0759-2.

B.-M. Ge · Y.-L. Song $(\bowtie)$

Key Laboratory of Animal Ecology and Conservation Biology,

Institute of Zoology, Chinese Academy of Sciences,

Beijing 100101, People's Republic of China

E-mail: songyl@ioz.ac.cn

Tel.: + 86-10-64807127

Fax: + 86-10-64807099

B.-M. Ge

Graduate University of Chinese Academy of Sciences,

Beijing 100049, People's Republic of China

T.-P. Guan

College of Life Sciences, Beijing Normal University,

Beijing 100875, People's Republic of China

D. Powell

Department of Mammalogy, Wildlife Conservation Society,

Bronx Zoo, New York 10460, USA

\section{W. J. McShea}

Smithsonian's Conservation Biology Institute,

National Zoological Park, 1500 Remount Rd.,

Front Royal, VA 22630, USA
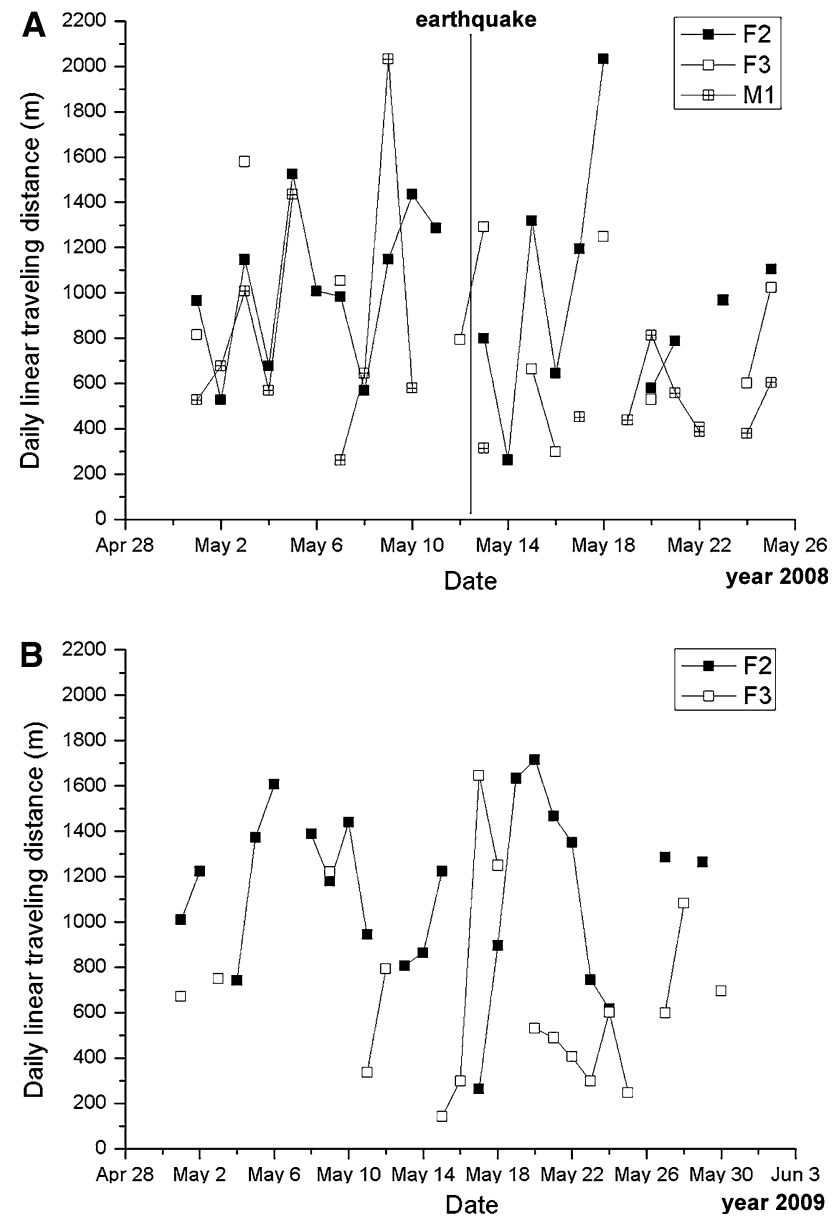